\title{
GCU
}

Glasgow Caledonian

University

University for the Common Good

\section{Investigating the prevalence of anxiety and depression in people living with patellofemoral pain in the UK: the Dep-Pf Study}

Wride, James; Bannigan, Katrina

Published in:

Scandinavian Journal of Pain

DOI:

10.1515/sjpain-2018-0347

Publication date:

2019

Document Version

Author accepted manuscript

Link to publication in ResearchOnline

Citation for published version (Harvard):

Wride, J \& Bannigan, K 2019, 'Investigating the prevalence of anxiety and depression in people living with patellofemoral pain in the UK: the Dep-Pf Study', Scandinavian Journal of Pain, vol. 19, no. 2, pp. 375-382. https://doi.org/10.1515/sjpain-2018-0347

\section{General rights}

Copyright and moral rights for the publications made accessible in the public portal are retained by the authors and/or other copyright owners and it is a condition of accessing publications that users recognise and abide by the legal requirements associated with these rights.

Take down policy

If you believe that this document breaches copyright please view our takedown policy at https://edshare.gcu.ac.uk/id/eprint/5179 for details of how to contact us. 


\section{Investigating the prevalence of anxiety and depression in people living with patellofemoral pain in the UK: The Dep-Pf Study}

\section{ABSTRACT}

\section{Background and Aims}

3 Patellofemoral pain (PFP) is a common knee condition causing pain around or behind

4 the kneecap which is exacerbated by certain activities. Traditionally it has been viewed

5 as a self-limiting condition. Recent research proves this is not the case and the

6 evidence for poor long-term outcomes is growing. Whilst the evidence base for PFP

7 treatment and the understanding of its aetiology is improving, it remains a complex and

8 difficult to treat condition. In many physical conditions, it has been shown that anxiety

9 and depression negatively affect both their management and duration. It is unclear how

10 prevalent anxiety and depression are in PFP. This study aimed to identify the

11 prevalence of anxiety and depression in people living with PFP in the UK.

\section{Methods}

13 In order to investigate this, a cross-sectional online survey was undertaken. Four

14 hundred participants with self-reported symptoms of PFP were recruited through a

15 tailored social media campaign, using modified snowball sampling. Eligibility criteria

16 were i) aged between 18 and 44, ii) self-reported symptoms of PFP (using accepted

17 criteria) iii) resident in the UK. Exclusion criteria were previous history of patella

18 dislocation or previous surgery to affected knee. The survey recorded demographic

19 information, previous treatment for both PFP and anxiety and depression, the Hospital 
20 Anxiety and Depression Scale and the Anterior Knee Pain Scale. Ethical approval was

21 gained from a University of Plymouth Ethics Committee.

\section{Results}

23 Half $(49.5 \% ; n=198)$ of respondents were classified as experiencing anxiety and $20.8 \%$

$24(n=83)$ as experiencing depression. The levels of anxiety and depression identified in

25 this study are higher than those found in the general population (5.9-7.8\% and $3.3-7.8 \%$

26 respectively). This mirrors results which have been reported in other studies into PFP in

27 different settings and with other musculoskeletal conditions, such as osteoarthritis and

28 contracted shoulder.

\section{Conclusions}

30 Anxiety and depression are more common in people living with PFP than in the general

31 population. These findings support the need for greater research into the effects of

32 psychological factors, such as anxiety and depression, in PFP. A key area of future

33 research will be to determine whether these psychological factors affect treatment

34 outcomes in people living with PFP.

\section{Implications}

This is the first study to investigate the prevalence of anxiety and depression in people living with patellofemoral pain in the UK. This study shows that anxiety and depression are very common in people living with patellofemoral pain. The need for further work into the effects of psychological factors in patellofemoral pain is indicated.

$\underline{\text { Keywords }}$

37 Patellofemoral; Knee; Anxiety; Depression; Prevalence; Mental Health 
39 Patellofemoral pain (PFP) is a common knee condition (1) generally affecting younger and more active people (2). It is characterised by pain around or behind the patella

41 aggravated by weight bearing activity with the knee in a flexed position (3). It has

42 traditionally been viewed as a self-limiting condition, however more recent research has

43 shown that over $40 \%$ of those receiving treatment for PFP will still have symptoms after

44 a year (4) with one in four reporting ongoing pain after 20 years (5). The impact of living 45 with PFP is becoming clear, affecting activity levels $(6)$, social participation $(7,8)$ and 46 Health related Quality of Life (8). Historically, research has focussed on the anatomical 47 and biomechanical causes of PFP (9-11), however this is starting to change. Recently 48 best practice guidelines have been published $(12,13)$ which provide guidance as to the 49 optimal management of PFP. Despite this PFP remains a complex and challenging 50 condition to treat $(14,15)$ and many people still continue to experience symptoms even 51 with optimal management (4).

52 In other musculoskeletal conditions it has been shown that anxiety and depression are 53 more common in these populations than the general population, with figures ranging

54 from $16-30 \%$ in those living with musculoskeletal conditions (16-18) compared with 3.3$557.8 \%$ in the general UK population (19). This has led to further work to investigate the 56 effects of psychological changes on the management and treatment of these conditions 57 (20-22). It has been shown that increased levels of anxiety and depression are 58 associated with greater persistence of the condition (22), increased acute pain (21), 59 slower recovery (20) and greater risk of re-occurrence (23). Despite this there has been 60 little work to investigate anxiety and depression in PFP (24). 
61 A recent systematic review of psychological features in PFP (24) identified few studies

62 investigating the prevalence of anxiety and depression with more extensive literature on

63 the effects of kinesiophopbia and catastrophizing behaviour. Those studies which do

64 exist reporting anxiety and depression were generally conducted with small sample

65 sizes and using a variety of disparate outcome measures (24). This limited the ability to

66 perform any meta-analyses to identify the true picture of anxiety and depression in PFP

67 with only a single study (25) reporting clear prevalence figures for anxiety and

68 depression. Domenech et al (25) investigated the prevalence of anxiety and depression

69 in Spanish tertiary care PFP patients. This study reported the prevalence of anxiety

$70(30 \%)$ and depression (16\%) in 97 consecutive patients attending an orthopaedic clinic.

71 However, this is not representative of the majority of PFP patients in the UK who are

72 managed in a primary care setting. Attendance at an orthopaedic clinic would suggest

73 increased severity and chronicity of the condition and, as such, these results cannot be

74 considered representative of the general PFP population. To the best of our knowledge,

75 there had been no UK based studies investigating anxiety and depression in people

76 living with PFP.

77 The aim of this study was to identify the prevalence of anxiety and depression in people

78 living with PFP in the UK and whether there are any links between the severity of PFP

79 and anxiety and depression.

80

\section{Study Design}


83 A cross-sectional online study design was used to gain a snap-shot of the prevalence of

84 anxiety and depression in people living with PFP in the UK population. An online

85 approach, using Bristol Online Surveys (now Online Surveys), was used to reach a

86 wide-ranging and diverse population which may not have been available from a more

87 traditional outpatient centred recruitment strategy. The study was opened on $01^{\text {st }}$ March

882017 and closed on $09^{\text {th }}$ May 2017 as the required sample size had been achieved.

89 Participants were provided with a detailed information sheet and could withdraw at any

90 time during or up until two weeks after completion of the survey. Ethical approval was

91 gained from University of Plymouth Faculty of Health \& Human Sciences, Schools of

92 Medicine and Dentistry Research Ethics Committee (Reference 16/17-257)

93

$94 \quad$ Participants

95 A sample size of 330 was calculated, using Raosoft Sample Size calculator, based on

96 an estimated UK population of 675,000 people living with PFP in our age range [based

97 upon a minimum $3 \%$ prevalence $(3,26)$, the UK population aged $15-44(27)]$ and a

98 prevalence of anxiety and depression of $30 \%$ based on the figures found by Domenech

99 in PFP and reported in other conditions $(16-18,25)$. The higher figure of $30 \%$ was

100 chosen based on the figures for anxiety (25) to reduce the risk of underpowering the

101 study. As there is no pre-existing sampling frame participants were recruited from a variety

102 of online sources (Facebook, Twitter, Forums, Special Interest groups, such as parkrun)

103 who identified as having PFP based on accepted criteria (3). Recruitment was capped

104 at 400 completed surveys. Whilst this allowed for the potential of over recruitment, this

105 enabled people who had begun completing the survey the opportunity to complete it 
106 once the calculated sample size was completed and to allow for any withdrawals

107 following the closing of recruitment. Eligibility criteria were i) adults aged between 18

108 and 44, ii) self-reported symptoms of PFP of pain when loading the knee in a flexed

109 position, such as running, jumping, squatting, hopping (3) iii) resident in the UK.

110 Exclusion criteria were previous history of patella dislocation or previous surgery to

111 affected knee (3).

112 Outcome measures

113 A questionnaire was developed to address our research question. The data collected is 114 summarised in Table 1.

\section{Statistical analysis}

117 Data was analysed with IBM SPSS Statistics (version 23.0). The sociodemographic 118 characteristics of the respondents are reported as percentages and numbers.

119 Prevalence of anxiety and depression were calculated as percentages of total sample.

120 Independent samples t-tests were used to compare continuous variables such as age 121 and HADS and AKPS scores. Chi-squared tests was used to compare categorical 122 variables such as gender, previous history of anxiety and depression and duration of 123 symptoms (categorical as grouped) with current HADS and AKPS scores. Correlation

124 between severity of PFP symptoms (NRS and AKPS) and severity of anxiety and 125 depression was assessed using Pearsons correlation co-efficient. Tests for normality 126 were not run as the sample size was in excess of that required for Central Limit 
127 Theorem assumptions of normality (28). Levels of statistical significance were set at $128 \quad p<0.05$.

\section{RESULTS}

130 The survey was accessed 2,386 times, with 1,894 not progressing beyond the consent 131 page and 162 people being excluded as they did not meet the inclusion criteria. The

132 demographics of the participants are summarised in table 2, as those excluded did not

133 complete the demographic information this is not available. Scores for the HADS-A,

134 HADS-D, AKPS and NRS are presented in table 3.

\section{Prevalence of anxiety and depression}

137 Almost half $(49.5 \% ; n=198)$ of respondents scored $\geq 8$ on the HADS-A (29) indicating

138 the presence of anxiety. One in five respondents $(20.8 \% ; n=83)$ scored $\geq 8(29)$ on the 139 HADS-D indicating depressive symptoms. When combined this showed that $53 \%(n=$ 140215 ) of respondents were living with anxiety and/or depression.

\section{Age}

142 Respondents with a HADS-A score suggesting anxiety were shown to be younger than

143 those who were not (mean age $=33.55 \vee 35.3$ ) following an independent samples t-test

$144(p=0.015)$. In those with scores suggesting depressive symptoms no significant

145 difference was identified (mean age $=34.55 \vee 34.4 ; p=0.86)($ Table 4$)$.

\section{Gender}


148 A chi-squared test for independence (with Yates' Continuity Correction) indicated a 149 significant association between gender and anxiety $(p=0.001)$. Adjusted residual 150 scores (4.6) indicated a greater than expected number of females with anxiety. No 151 significant association was seen between depressive symptoms and gender $(p=0.628)$.

\section{History of anxiety and depression}

153 A significant association between a previous diagnosis of anxiety and/or depression and

154 a current score indicating anxiety or depressive symptoms was found using chi155 squared. This was found to be stronger for anxiety ( $p h i=-0.33 ; p=0.001$ ) than 156 depression $(\mathrm{phi}=-0.22 ; \mathrm{p}=0.001)$.

\section{Association with knee symptoms}

158 A significant association between AKPS score and both anxiety and depressive 159 symptoms was identified using an independent samples t-test (Table 4). Pearson 160 product-moment correlations showed a small negative correlation between lower scores 161 on the AKPS and higher levels of anxiety $(r=-0.15 ; p<0.001)$, and a small to medium

162 negative correlation between lower AKPS and higher levels of depressive symptoms ( $r$ $163=-0.26 ; p<0.001)$.

164 No significant association was identified between the NRS scores and either anxiety 165 and depressive symptoms.

\section{Duration of Symptoms}

167 A chi-squared test identified no significant association between the duration of PFP and 168 the presence of anxiety $(p=0.73)$ or depressive symptoms $(p=0.39)$. 


\section{DISCUSSION}

171 Until recently the role of psychological factors in PFP has received little attention. The

172 recent publication of a systematic review (24), has emphasised the paucity of evidence

173 in this area. The current study has suggested that over half of people living with PFP

174 are experiencing anxiety and/or depressive symptoms. There seems to be a small

175 correlation between increased severity of PFP symptoms (AKPS) and increased levels

176 of anxiety and depressive symptoms. This is more marked with depressive symptoms.

177 To the best of our knowledge this is the first study to investigate the prevalence of

178 anxiety and depression in people living with PFP in the UK population.

Anxiety and depression prevalence in PFP

181 The levels of anxiety and depressive symptoms shown in this study are much higher

182 than those found in the general population (anxiety: 49.5\% v 5.9-7.8\%; depressive

183 symptoms 20.8 v 3.3-7.8\% (19)). Whilst some caution must be exercised with these

184 figures due to the potential for the HADS to overestimate anxiety and depression (30),

185 and the broad inclusion criteria of the study, this suggests a significant proportion of the

186 study population are experiencing anxiety and depression in addition to the known

187 physical effects of PFP.

188 Despite these concerns, the results echo those reported in other studies. Domenech et 189 al (25) identified similar rates of anxiety (30\%) and depression (16\%) in people with 
190 PFP $(n=97)$ in a tertiary setting. They also reported similar mean scores for HADS-A 191 (7.9) and HADS-D (5.3). Direct comparisons with this study should be made with

192 caution as it is not clear as to the threshold used to identify anxiety and depression.

193 Axford et al. (18) suggested a rate of depression in excess of $40 \%$ in osteoarthritis, 194 however this has recently been superseded by the systematic review by Stubbs et al. 195 (16), which suggested figures of around $20 \%$ may be more accurate for both anxiety 196 and depression in osteoarthritis. Similar figures have also been reported in contracted 197 shoulder (17) and low back pain (31). This suggests that the findings in this study are 198 realistic, despite concerns regarding the accuracy of the HADS as a measurement tool.

199 The growing evidence from these studies suggest that higher levels of anxiety and 200 depression are found across a number of MSK conditions.

201 The figures for anxiety in this study suggest a high prevalence in people living with PFP.

202 However, this must be viewed in the context of the study population. The study 203 population was predominately female $(67.6 \%)$ and relatively young (mean age 34.4 ).

204 Previous studies have shown that anxiety is more common in younger women than in 205 the general population (32). It must be considered whether the results found reflect the 206 demographics of the study. Whilst there was a significant difference in the prevalence of 207 anxiety between men and women, this alone does not explain the prevalence of anxiety 208 in this study.

210 The results of this study identified a correlation between greater severity of PFP

211 symptoms (as measured on the AKPS) and higher scores recorded on the two elements 
212 of the HADS. The magnitude of correlation was small for anxiety $(r=-0.15 ; p<0.001)$

213 and small to medium for depressive symptoms $(r=-0.26 ; p<0.001)$. However the large

214 numbers involved in this study suggest that this statistical significance may be due to

215 the sample size (33). When we consider the strength of the relationship between the

216 two sets of variables $(-0.15$ and -0.26$)$, and the co-efficient of determination $(2.25 \%$ and

$2176.76 \%$ respectively), the low levels of these figures suggest that there is only a weak

218 influence of the level of PFP symptoms on the level of anxiety and depressive

219 symptoms (33). When the figures are examined the mean difference in AKPS between

220 those with and without anxiety and depressive symptoms (Table 4), whilst statistically

221 significant, fall well below the minimal clinically important difference for the AKPS (34).

222 Domenech et al. (25) reported correlations of -0.61 and 0.57 for depression and anxiety 223 (measured with the HADS) with the Lysholm score. Piva et al (35) reported a correlation

224 of -0.45 between the KOS-ADLS and Beck Anxiety Index. This reinforces the concerns

225 raised by Maclachlan et al. (24) regarding the heterogeneity of outcome measures used

226 in PFP research. It could be argued that had the current study taken a different

227 approach to data analysis, such as a binary approach to anxiety and depression, then a

228 stronger relationship may have been found between these factors, as suggested by

229 previous studies.

230 Irrespective of the magnitude of the relationships identified by Piva et al. (36),

231 Domenech et al. (25) and the current study, all agree that there is a relationship

232 between severity of PFP symptoms and anxiety and depression. A previous meta-

233 analysis investigating chronic pain has suggested that increased levels of depression

234 are associated with the duration of symptoms, severity of symptoms and number of 
235 joints affected (37). Interestingly this current study has suggested that neither the

236 duration of symptoms nor level of pain (measured by NRS) affect the levels of anxiety

237 and depression in PFP. This may reflect the nature of the population targeted in this

238 study. Previous studies have concentrated on people attending a variety of secondary

239 and tertiary healthcare settings, whereas this study has recruited people whether they

240 were receiving formal treatment or not. PFP is not considered to be a degenerative

241 condition, with many people having symptoms over a long time period $(4,5)$. This may

242 suggest that some of the respondents included in this study with long term symptoms

243 have been managing their condition well, with pain at a low level.

\section{$244 \quad$ Future Research}

245 Further research would be beneficial to identify the effects, if any, of anxiety and

246 depression on treatment outcomes in PFP. Should this show that anxiety and

247 depression does have a negative impact on treatment outcomes then further studies

248 investigating the treatment of anxiety and depression in PFP would be warranted.

249 Whilst this study has shown that there are high levels of anxiety and depression evident

250 in people living with PFP we are unable to draw any inferences as to why this is. Further

251 qualitative work could identify any common themes about what contributes to the

252 development of anxiety and depression. This could then be progressed to investigate

253 whether there is a causative relationship between PFP and anxiety and depression and

254 in which direction it exists.

\section{Strengths and Limitations}


256 This study benefits from the fact we were able to over-recruit (target 330 , actual 400 )

257 ensuring that we were able to adequately power all the calculations for the statistical

258 analysis. Underpowered studies are more prone to both type I and type II errors (38)

259 with the risk of both false positive results and 'true' results not reaching statistical

260 significance. This is a weakness seen in many studies across all fields (39). The

261 number of respondents in this study was larger than any previous study looking at

262 mental health in PFP $(24,25)$.

263 The study also benefitted from using robust outcome measures (AKPS, HADS and

264 NRS) to determine our primary outcomes (PFP severity and anxiety and depression)

265 with good reliability and validity. These measures have been identified as the most

266 commonly used outcome tools in PFP (24), meaning that the results of this study can be

267 easily incorporated into any future meta-analyses.

268 There were a number of clear limitations identified within this study. Foremost among

269 these was the lack of clinical diagnosis for PFP amongst the respondents. Clinical

270 assessment by an experienced clinician is considered the gold standard for diagnosis of

$271 \operatorname{PFP}(3,12)$. This was not a practical option for this study due to its online nature.

272 Instead, the criteria developed by Crossley et al. (2016) were used to classify someone

273 as living with PFP. This raises the likelihood that other knee conditions were included in

274 this study. The use of established inclusion and exclusion criteria should have mitigated 275 this risk.

276 The online nature of the study also contributed to another significant weakness within

277 the study design. Anxiety and depression are complex, multifactorial conditions unlikely

278 to be directly attributable to a single cause $(40,41)$. Recent studies have also shown that 
279 PFP is highly associated with multi-site musculoskeletal pain (42). As we were unable to 280 collect extensive medical history for each participant we are unable to account for the 281 effects of other musculoskeletal or chronic health conditions in this study. This limits our 282 ability to truly say that PFP is associated with higher levels of anxiety and depression.

283 This is shown by the high number of respondents identifying as having a history of 284 anxiety or depression.

285 Another limitation identified in this study is the risk of self-selection bias. Since our 286 respondents were able to choose whether to participate in the study, it is not possible to 287 say that this was a representative sample of the population as a whole (43). It is well 288 established that ethnic minorities are generally under-represented in research 289 participation (44) and that educated white females are disproportionally represented in 290 research studies (45). This is shown in this study with an over-representation of those 291 identifying as white $(94.8 \% ; n=379)$ compared with that expected from the latest Office 292 for National Statistics figures (86\%) (46). Whilst this is a common finding across many 293 fields of research, it raises the question about what information may be being missed in 294 these groups. This is an area which would benefit from greater attention in future 295 research in order to ensure a wider, and more representative, study population.

\section{CONCLUSION}

297 Anxiety and depression in people living with PFP is more common than in the general 298 UK population. In this study almost half of people meeting the inclusion criteria for PFP 299 had a score on the HADS-A indicating anxiety and one in five were identified as 300 experiencing depressive symptoms on the HADS-D. To the best of our knowledge this 
301 is the first study to investigate the prevalence of anxiety and depression of people living 302 with PFP in the general population rather than those who are engaged in healthcare 303 services. This study cannot draw any causal links between anxiety and depression and 304 PFP, but it does highlight the strong association between the two conditions. The results 305 of this study add further strength to the need for additional work into the effects of 306 mental well-being in PFP. This is an area which has previously received little attention. 
308 Research Funding: This research did not receive any specific grant from funding

309 agencies in the public, commercial, or not-for-profit sectors. JW is funded by the NIHR

310 as part of the NIHR Clinical Academic Pathway.

311 Conflict of Interest declaration: None declared

312 Informed Consent: Informed consent has been obtained from all individuals included in

313 this study.

314 Ethical Approval: Ethical approval was gained from University of Plymouth Faculty of

315 Health \& Human Sciences, Schools of Medicine and Dentistry Research Ethics

316 Committee (Reference 16/17-257)

317 


\begin{tabular}{|c|c|}
\hline Demographics & $\begin{array}{l}\text { - } \text { Age } \\
\text { - Gender } \\
\text { - Educational level, } \\
\text { - Employment status } \\
\text { - Ethnicity. }\end{array}$ \\
\hline History & $\begin{array}{l}\text { - } \text { Duration of knee pain symptoms. } \\
\text { - Any previous treatment for this. } \\
\text { - } \text { Previous diagnosis of either anxiety and/or depression } \\
\text { - } \quad \text { Any current treatment for anxiety and/or depression }\end{array}$ \\
\hline $\begin{array}{l}\text { Anxiety and } \\
\text { Depression }\end{array}$ & 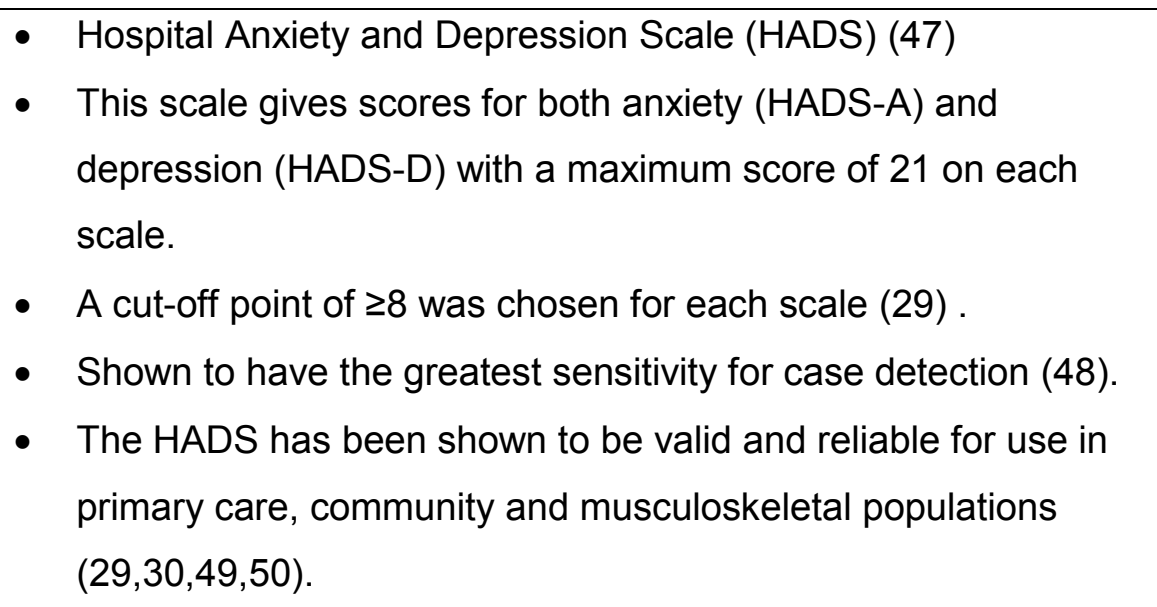 \\
\hline Knee symptoms & $\begin{array}{l}\text { - Two measures used to assess severity of PFP symptoms. } \\
\text { - A numerical rating scale (NRS) for pain over the previous } 24 \\
\text { hours was used to assess current pain. } \\
\text { - Shown to be valid and reliable in both general musculoskeletal } \\
\text { conditions (51) and PFP (34). } \\
\text { - Anterior Knee Pain Scale (AKPS) (52) was used to assess level } \\
\text { of function. } \\
\text { - Shown to be both valid and reliable in PFP patients (53) and } \\
\text { requires little guidance in completion (54). }\end{array}$ \\
\hline
\end{tabular}




\begin{tabular}{|c|c|c|c|}
\hline Age, mean (SD) & 34.4 & (7.18) & 400 \\
\hline Gender - female, n (\%) & 268 & (67.3) & 397 \\
\hline \multicolumn{4}{|l|}{ Ethnicity, n (\%) } \\
\hline White & 379 & $(94.8)$ & \multirow{5}{*}{398} \\
\hline Asian or Asian British & 9 & $(2.3)$ & \\
\hline Black or Black British & 3 & $(0.8)$ & \\
\hline Mixed / Multiple ethnic groups & 5 & $(1.3)$ & \\
\hline Other ethnic background & 2 & $(0.5)$ & \\
\hline \multicolumn{4}{|l|}{ Education, $\mathrm{n}(\%)$} \\
\hline GCSE / O Level & 26 & (6.5) & \multirow{7}{*}{398} \\
\hline AS Level & 5 & $(1.3)$ & \\
\hline A Level & 36 & (9.0) & \\
\hline NVQ or other vocational & 39 & $(9.8)$ & \\
\hline First Degree (including foundation degree) & 177 & $(44.3)$ & \\
\hline University Higher Degree (Msc or PhD) & 111 & $(27.8)$ & \\
\hline None of the above & 4 & $(1.0)$ & \\
\hline \multicolumn{4}{|l|}{ Employment Status, n (\%) } \\
\hline Employed / Self employed & 352 & (88.0) & \multirow{5}{*}{399} \\
\hline Unemployed & 7 & $(1.8)$ & \\
\hline Looking after home/ family & 13 & (3.3) & \\
\hline Student / Full time education & 25 & (6.3) & \\
\hline Unable to work & 2 & $(0.5)$ & \\
\hline \multicolumn{4}{|l|}{ Pain Duration, $\mathrm{n}(\%)$} \\
\hline$<3$ Months & 55 & $(13.8)$ & \multirow{7}{*}{400} \\
\hline 3-6 months & 54 & $(13.5)$ & \\
\hline $6-12$ months & 42 & $(10.5)$ & \\
\hline $12-18$ months & 40 & $(10)$ & \\
\hline 18-24 months & 27 & $(6.8)$ & \\
\hline $2-5$ years & 84 & $(21.0)$ & \\
\hline$>5$ years & 98 & $(24.5)$ & \\
\hline \multicolumn{4}{|l|}{ Affected Knee, n (\%) } \\
\hline Right & 111 & $(27.8)$ & \multirow{3}{*}{400} \\
\hline Left & 126 & $(31.5)$ & \\
\hline Both & 163 & $(40.8)$ & \\
\hline Previous treatment for PFP - Yes, n (\%) & 187 & (46.8) & 400 \\
\hline $\begin{array}{l}\text { Previous Diagnosis of anxiety or depression } \\
\text { - Yes, } n(\%)\end{array}$ & 136 & (34.8) & 400 \\
\hline $\begin{array}{l}\text { Receiving Treatment for anxiety or depression } \\
- \text { Yes, } n(\%)\end{array}$ & 45 & (11.3) & 400 \\
\hline
\end{tabular}


Table 3: Mean values of key outcome measure for study participants. (SD = Standard deviation)

\begin{tabular}{|l|l|l|}
\hline Outcome Measure & Mean & SD \\
\hline Numerical Rating Scale - Pain 0-10, & 3.45 & $(2.2)$ \\
\hline Hospital Anxiety and Depression Scale - & 7.75 & $(4.2)$ \\
\hline Hospital Anxiety and Depression Scale - & & \\
\hline Depression 0-21,) & 4.65 & $(3.5)$ \\
\hline Anterior Knee Pain Scale 0-100, & & $(10.4)$ \\
\hline
\end{tabular}

322

323 
325 AKPS = Anterior Knee Pain Scale)

\begin{tabular}{|l|l|l|l|l|l|l|}
\hline \multirow{2}{*}{ Variable } & \multicolumn{3}{|c|}{ Depression } & \multicolumn{3}{c|}{ Anxiety } \\
\cline { 2 - 7 } & \multicolumn{1}{|c|}{$<$} & $\mathbf{8}$ & & \multicolumn{2}{c|}{ <8 } & \\
\cline { 2 - 7 } & $(\mathbf{n = 3 1 7 )}$ & $(\mathbf{n = 8 3 )}$ & $p$ & $(\mathbf{n = 2 0 2 )}$ & (n= 198) & $p$ \\
\hline Age & $34.40(7.15)$ & $34.55(7.35)$ & 0.86 & $35.30(7.13)$ & $33.55(7.14)$ & 0.015 \\
\hline NRS & $3.45(2.18)$ & $3.45(2.35)$ & 0.994 & $3.32(2.23)$ & $3.58(2.19)$ & 0.25 \\
\hline AKPS & $77.61(10.23)$ & $73.24(10.15)$ & 0.001 & $78.37(9.96)$ & $75(10.49)$ & 0.001 \\
\hline
\end{tabular}

326 
329 1. van Middelkoop M, van Linschoten R, Berger MY, Koes BW, BiermaZeinstra SM. Knee complaints seen in general practice: active sport participants versus non-sport participants. BMC Musculoskelet Disord [Internet]. $2008 \operatorname{Dec}$ 19;9(1):36. Available from: http://bmcmusculoskeletdisord.biomedcentral.com/articles/10.1186/14

2. Rathleff MS, Roos EM, Olesen JL, Rasmussen S. Early intervention

3. Crossley KM, Stefanik JJ, Selfe J, Collins NJ, Davis IS, Powers CM, McConnell J, Vicenzino B, Bazett-Jones DM, Esculier J-F, Morrissey D, Callaghan MJ. 2016 Patellofemoral pain consensus statement from the 4th International Patellofemoral Pain Research Retreat, Manchester. Part 1: Terminology, definitions, clinical examination, natural history, patellofemoral osteoarthritis and patient-reported outcome. Br J Sports Med [Internet]. 2016 Jul;50(14):839-43. Available from: http://bjsm.bmj.com/lookup/doi/10.1136/bjsports-2016096384

4. Collins NJ, Bierma-Zeinstra SMA, Crossley KM, van Linschoten RL, Vicenzino B, van Middelkoop M. Prognostic factors for patellofemoral pain: a multicentre observational analysis. Br J Sports Med [Internet]. 2013 Mar;47(4):227-33. Available from: 
http://bjsm.bmj.com/lookup/doi/10.1136/bjsports-2012-091696

353

5. Nimon G, Murray D, Sandow M, Goodfellow J. Natural history of anterior knee pain: a 14- to 20-year follow-up of nonoperative management. J Pediatr Orthop [Internet]. 1998 Jan 1;18(1):118-22. Available from: http://content.wkhealth.com/linkback/openurl?sid=WKPTLP:landingpa ge\&an=00004694-199801000-00021

6. Glaviano NR, Baellow A, Saliba S, Al. E, Tatman M, Olesen JL. Physical activity levels in individuals with and without patellofemoral pain. Phys Ther Sport [Internet]. 2017;25(0):2432-9. Available from: http://linkinghub.elsevier.com/retrieve/pii/S1466853X17301530

7. Smith BE, Moffatt F, Hendrick P, Bateman M, Rathleff MS, Selfe J, Smith TO, Logan P. The experience of living with patellofemoral pain-loss, confusion and fear-avoidance: a UK qualitative study. BMJ Open [Internet]. 2018;8(1):e018624. Available from: http://bmjopen.bmj.com/lookup/doi/10.1136/bmjopen-2017-018624

8. Coburn SL, Barton CJ, Filbay SR, Hart HF, Rathleff MS, Crossley KM. Quality of life in individuals with patellofemoral pain: A systematic review including meta-analysis. Phys Ther Sport [Internet]. 2018;33(2018):96-108. Available from: https://doi.org/10.1016/j.ptsp.2018.06.006

9. Myer GD, Ford KR, Barber Foss KD, Goodman A, Ceasar A, Rauh MJ, Divine JG, Hewett TE. The incidence and potential pathomechanics of patellofemoral pain in female athletes. Clin Biomech. 2010;25(7):700-7. 
377 10. Powers CM, Bolgla L a, Callaghan MJ, Collins N, Sheehan FT.

Patellofemoral pain: proximal, distal, and local factors, 2nd International Research Retreat. J Orthop Sports Phys Ther [Internet]. 2012;42(6):A1-54. Available from:

http://www.ncbi.nlm.nih.gov/pubmed/22660660

11. Noehren B, Scholz J, Davis I. The effect of real-time gait retraining on hip kinematics, pain and function in subjects with patellofemoral pain syndrome. Br J Sports Med [Internet]. 2011 Jul 1;45(9):691-6. Available from: http://www.ncbi.nlm.nih.gov/pubmed/20584755

12. Barton CJ, Lack S, Hemmings S, Tufail S, Morrissey D. The 'Best Practice Guide to Conservative Management of Patellofemoral Pain': incorporating level 1 evidence with expert clinical reasoning. $\mathrm{Br} \mathrm{J}$ Sports Med [Internet]. 2015 Jul;49(14):923-34. Available from:

13. Lack S, Neal B, De Oliveira Silva D, Barton CJ. How to manage patellofemoral pain - Understanding the multifactorial nature and treatment options. Phys Ther Sport [Internet]. 2018;32:155-66. http://bjsm.bmj.com/lookup/doi/10.1136/bjsports-2014-093637 Available from: https://doi.org/10.1016/j.ptsp.2018.04.010

14. Smith BE, Hendrick P, Bateman M, Moffatt F, Rathleff MS, Selfe J, Smith TO, Logan P. Current management strategies for patellofemoral pain: an online survey of 99 practising UK physiotherapists. BMC Musculoskelet Disord [Internet]. 2017 Dec 8;18(1):181. Available from: http://bmcmusculoskeletdisord.biomedcentral.com/articles/10.1186/s1 2891-017-1539-8

401 15. Papadopoulos KD, Noyes J, Barnes M, Jones JG, Thom JM. How do 
physiotherapists assess and treat patellofemoral pain syndrome in North Wales? A mixed method study. Int J Ther Rehabil.

405

406

407

408

409

410

411

412

413

414

415

416 2012;19(5):261-72.

16. Stubbs B, Aluko Y, Myint PK, Smith TO. Prevalence of depressive symptoms and anxiety in osteoarthritis: A systematic review and meta-analysis. Age Ageing. 2016;45(2):228-35.

17. Ding $\mathrm{H}$, Tang $\mathrm{Y}$, Xue $\mathrm{Y}$, Yang Z, Li Z, He D, Zhao $\mathrm{Y}$, Zong $\mathrm{Y}$. A report on the prevalence of depression and anxiety in patients with frozen shoulder and their relations to disease status. Psychol Health Med. 2014;19(6):730-7.

18. Axford J, Butt A, Heron C, Hammond J, Morgan J, Alavi A, Bolton J, Bland M. Prevalence of anxiety and depression in osteoarthritis: use of the Hospital Anxiety and Depression Scale as a screening tool. Clin Rheumatol. 2010;29(11):1277-83.

19. McManus S, P B, Jenkins R, Brugha T. Mental health and well-being in England: Adult Psychiatric Morbidity Survey 2014. Leeds; 2016.

20. Melloh M, Elfering A, Käser A, Salathé CR, Barz T, Aghayev E, Röder $\mathrm{C}$, Theis J-C. Depression Impacts the Course of Recovery in Patients with Acute Low-Back Pain. Behav Med [Internet]. 2013 Jul;39(3):80-9. Available from: http://www.ncbi.nlm.nih.gov/pubmed/23930900

21. Elfering A, Käser A, Melloh M. Relationship between depressive symptoms and acute low back pain at first medical consultation, three and six weeks of primary care. Psychol Health Med [Internet]. 2014 Mar 4;19(2):235-46. Available from: http://www.tandfonline.com/doi/abs/10.1080/13548506.2013.780131 
22. Rathbun AM, Stuart EA, Shardell M, Yau MS, Baumgarten M, Hochberg MC. Dynamic Effects of Depressive Symptoms on Osteoarthritis Knee Pain. Arthritis Care Res (Hoboken) [Internet]. 2017 Mar;11(5):475-6. Available from: http://doi.wiley.com/10.1002/acr.23239

23. Pinheiro MB, Ferreira ML, Refshauge K, Ordoñana JR, Machado GC, Prado LR, Maher CG, Ferreira PH. Symptoms of Depression and Risk of New Episodes of Low Back Pain: A Systematic Review and MetaAnalysis. Arthritis Care Res (Hoboken) [Internet]. 2015;67(11):1591603. Available from: http://doi.wiley.com/10.1002/acr.22619

24. Maclachlan LR, Collins NJ, Matthews MLG, Hodges PW, Vicenzino B. The psychological features of patellofemoral pain: a systematic review. Br J Sports Med [Internet]. 2017;51(9):732-42. Available from: http://bjsm.bmj.com/lookup/doi/10.1136/bjsports-2016-096705

25. Domenech J, Sanchis-Alfonso V, López L, Espejo B. Influence of kinesiophobia and catastrophizing on pain and disability in anterior knee pain patients. Knee Surgery, Sport Traumatol Arthrosc [Internet]. 2013 Jul 19;21(7):1562-8. Available from: http://link.springer.com/10.1007/s00167-012-2238-5

26. Lack S, Barton CJ, Sohan O, Crossley K, Morrissey D. Proximal muscle rehabilitation is effective for patellofemoral pain: a systematic review with meta-analysis. Br J Sports Med [Internet]. 2015 Nov;49(21):1365-76. Available from: http://dx.doi.org/10.1136/

27. Office for National Statistics. Population Estimates for UK, England and Wales, Scotland and Northern Ireland, Mid 2015 [Internet]. 2016 
[cited 2016 Oct 10]. p. 1-9. Available from: http://www.ons.gov.uk/ons/rel/pop-estimate/population-estimates-foruk--england-and-wales--scotland-and-northern-ireland/mid2014/index.html

28. Daniel WW, Cross CL. Biostatistics. Basic Concepts and Methodology for the Health Sciences. 10th ed. John Wiley \& Sons; 2013. 960 p.

29. Covic T, Cumming SR, Pallant JF, Manolios N, Emery P, Conaghan PG, Tennant A. Depression and anxiety in patients with rheumatoid arthritis: prevalence rates based on a comparison of the Depression, Anxiety and Stress Scale (DASS) and the hospital, Anxiety and Depression Scale (HADS). BMC Psychiatry [Internet]. 2012;12(1):6. Available from: http://www.pubmedcentral.nih.gov/articlerender.fcgi?artid=3285517\&t ool=pmcentrez\&rendertype=abstract

30. Cameron IM, Cardy A, Crawford JR, du Toit SW, Hay S, Lawton K, Mitchell K, Sharma S, Shivaprasad S, Winning S, Reid IC. Measuring depression severity in general practice: discriminatory performance of the PHQ-9, HADS-D, and BDI-II. Br J Gen Pract [Internet]. 2011 Jul 1;61(588):419-26. Available from: http://bjgp.org/cgi/doi/10.3399/bjgp11X583209

31. Currie SR, Wang J. Chronic back pain and major depression in the general Canadian population. Pain. 2004;107(1-2):54-60.

32. Remes O, Brayne C, van der Linde R, Lafortune L. A systematic review of reviews on the prevalence of anxiety disorders in adult populations. Brain Behav. 2016;6(7). 
477 33. Pallant J. SPSS survival manual: a step by step guide to data analysis using SPSS. 6th ed. Step by step guide to data analysis using the SPSS program. Maidenhead: Open University Press; 2016.

480

481

482

483

484

485

486

487

488

489

490

491

492

493

494

495

496

497

498

499

500

501

34. Crossley KM, Bennell KL, Cowan SM, Green S. Analysis of outcome measures for persons with patellofemoral pain: Which are reliable and valid? Arch Phys Med Rehabil. 2004;85(5):815-22.

35. Piva SR, Fitzgerald GK, Irrgang JJ, Fritz JM, Wisniewski S, McGinty GT, Childs JD, Domenec MA, Jones S, Delitto A. Associates of Physical Function and Pain in Patients with Patellofemoral Pain Syndrome. Arch Phys Med Rehabil [Internet]. 2009 Feb 1 [cited 2016 Oct 5];90(2):285-95. Available from: http://linkinghub.elsevier.com/retrieve/pii/S0003999308016328

36. Piva S, Fitzgerald G, Wisniewski S, Delitto A. Predictors of pain and function outcome after rehabilitation in patients with patellofemoral pain syndrome. J Rehabil Med. 2009;41(8):604-12.

37. Gandhi R, Zywiel MG, Mahomed NN, Perruccio A V. Depression and the Overall Burden of Painful Joints: An Examination among Individuals Undergoing Hip and Knee Replacement for Osteoarthritis. Arthritis [Internet]. 2015;2015:1-6. Available from: http://www.hindawi.com/journals/arthritis/2015/327161/

38. Christley RM. Power and Error: Increased Risk of False Positive Results in Underpowered Studies. Open Epidemiol J [Internet]. 2010 Feb 1;3(1):16-9. Available from: http://benthamopen.com/ABSTRACT/TOEPIJ-3-16

39. Turner RM, Bird SM, Higgins JPT. The Impact of Study Size on Meta- 
analyses: Examination of Underpowered Studies in Cochrane Reviews. PLoS One [Internet]. 2013 Mar 27;8(3):e59202. Available from: http://dx.plos.org/10.1371/journal.pone.0059202

505

506

507

508

509

510

511

512

513

514

40. National Institute for Health and Clinical Excellence. Generalised anxiety disorder and panic disorder in adults: Management. Natl Inst Heal Clin Excell. 2011;(January):1-53.

41. National Institute for Health and Clinical Excellence. Depression in Adults: Recognition and Management Clinical Guideline: NICE Guideline [CG90]. Natl Collab Cent Ment Heal [Internet]. 2009;(April). Available from:

https://www.nice.org.uk/guidance/cg90/resources/depression-inadults-recognition-and-management-975742636741

42. Holden S, Rathleff MS, Roos EM, Jensen MB, Pourbordbari N, Graven-Nielsen T. Pain patterns during adolescence can be grouped into four pain classes with distinct profiles: A study on a population based cohort of 2953 adolescents. Eur J Pain [Internet]. 2017 Dec 27; Available from: http://doi.wiley.com/10.1002/ejp.1165

43. Bethlehem J. Selection Bias in Web Surveys. Int Stat Rev [Internet]. 2010 Jun 18;78(2):161-88. Available from: http://dx.doi.org/10.1111/j.1751-5823.2010.00112.x

44. Hood GA, Chowdhury TA, Griffiths CJ, Hood RKE, Mathews C, Hitman GA. The Mela Study: exploring barriers to diabetes research in black and minority ethnic groups. Prim Health Care Res Dev [Internet]. 2015;16(01):53-60. Available from: http://www.journals.cambridge.org/abstract_S1463423614000061 
45. Van Lange PAM, Schippers M, Balliet D. Who volunteers in psychology experiments? An empirical review of prosocial motivation in volunteering. Pers Individ Dif [Internet]. 2011 Aug;51(3):279-84. Available from: http://linkinghub.elsevier.com/retrieve/pii/S0191886910002850

46. Office for National Statistics. Ethnicity and National Identity in England and Wales [Internet]. 2012 [cited 2016 Nov 14]. Available from: http://www.ons.gov.uk/peoplepopulationandcommunity/culturalidentity/ ethnicity/articles/ethnicityandnationalidentityinenglandandwales/2012$12-11$

47. Zigmond AS, Snaith RP. The Hospital Anxiety and Depression Scale. Acta Psychiatr Scand. 1983 Jun;67(6):361-70.

48. Brennan C, Worrall-Davies A, McMillan D, Gilbody S, House A. The Hospital Anxiety and Depression Scale: A diagnostic meta-analysis of case-finding ability. J Psychosom Res [Internet]. 2010 Oct;69(4):3718. Available from: http://dx.doi.org/10.1016/j.jpsychores.2010.04.006

49. Turk DC, Dworkin RH, Trudeau JJ, Benson C, Biondi DM, Katz NP, Kim M. Validation of the Hospital Anxiety and Depression Scale in Patients With Acute Low Back Pain. J Pain. 2015;16(10):1012-21.

50. Cameron IM, Crawford JR, Lawton K, Reid IC. Psychometric comparison of PHQ-9 and HADS for measuring depression severity in primary care. Br J Gen Pract [Internet]. 2008 Jan 1;58(546):32-6. Available from: http://bjgp.org/cgi/doi/10.3399/bjgp08X263794

51. Hawker GA, Mian S, Kendzerska T, French M. Measures of adult pain: Visual Analog Scale for Pain (VAS Pain), Numeric Rating Scale 
for Pain (NRS Pain), McGill Pain Questionnaire (MPQ), Short-Form McGill Pain Questionnaire (SF-MPQ), Chronic Pain Grade Scale (CPGS), Short Form-36 Bodily Pain Scale (SF. Arthritis Care Res (Hoboken) [Internet]. $2011 \mathrm{Nov;63(S11):S240-52.} \mathrm{Available} \mathrm{from:}$ http://doi.wiley.com/10.1002/acr.20543

52. Kujala UM, Jaakkola LH, Koskinen SK, Taimela S, Hurme M, Nelimarkka O. Scoring of patellofemoral disorders. Arthrosc J Arthrosc Relat Surg [Internet]. 1993;9(2):159-63. Available from: http://linkinghub.elsevier.com/retrieve/pii/S0749806305803664

53. Singer B, Singer K. Anterior Knee Pain Scale. Aust J Physiother [Internet]. 2009;55(2):140. Available from: http://linkinghub.elsevier.com/retrieve/pii/S0004951409700480 patellofemoral pain syndrome: test retest reliability and interrelationships. Phys Ther Sport. 2000 May;1(2):32-41. 